\title{
What's Context Got To Do With It? An Exploration of Leadership Development Programs for the Agricultural Community
}

\author{
Eric K. Kaufman, Ph.D. \\ Assistant Professor \\ Department of Agricultural and Extension Education \\ Virginia Tech \\ 2270 Litton Reaves Hall (0343) \\ Blacksburg, VA 24061 \\ ekaufman@vt.edu
}

Richard J. Rateau, Ph.D.

Department of Agricultural and Extension Education

Virginia Tech

2270 Litton Reaves (0343)

Blacksburg VA 24061

rrateau@vt.edu

\section{Hannah S. Carter, Ph.D.}

Director,

Wedgworth Leadership Institute for Agriculture and Natural Resources

University of Florida

121B Bryant Hall

PO Box 112060

Gainesville, FL 32611

hscarter@ufl.edu

L. Rochelle Strickland, Ph.D.

LEAD21 Program Manager

University of Georgia

Agricultural Leadership - Athens

133 Four Towers Building

Athens, GA 30602

rstrick@uga.edu 


\begin{abstract}
One method to develop leaders is through leadership development programs designed specifically for an intended context. The International Leadership Association (ILA) provides questions for designing programs such programs. This article reflects data collected during the process of developing a leadership program serving the broader agricultural community in Virginia. The International Association of Programs for Agricultural Leadership (IAPAL) reports that programs for leadership development in agricultural contexts typically include 12 seminars over two years, with less than one-third of the seminars agriculturally related. The profile includes sources of financial support and allocation of administrative duties. A survey of agricultural leaders reveals a strong desire for such programming. The stakeholders sought a program including emerging and experienced leaders with travel for on-site experiential learning. The findings have implications for the state and broad leadership development. Those who develop leadership programs for other contexts may benefit from the guiding questions and data.
\end{abstract}

\title{
Introduction
}

"Our nation is in a leadership crisis, one that requires more and better leadership in all areas of our society" (Eich, 2008, p. 176). This is especially true for the complex world of agriculture, as agricultural professionals face daily challenges. The future success of the agricultural industry depends on strong leaders who can effectively address these challenges (Bradshaw \& Rudd, 2009; Diem \& Nikola, 2005; Kaufman \& Carter, 2005; Kaufman, Rateau, Ellis, Kasperbauer, \& Stacklin, 2010). Investment in leadership development is strong (Day, 2001), with a growing number of leadership development programs offered, costing billions of dollars annually (Riggio, 2008). However there is "little agreement about the best strategies [for developing leadership]" (Hackman \& Wageman, 2007, p. 43). Designing a quality leadership development program is difficult and requires a systematic approach that considers the unique contextual needs of the program (Bryne \& Rees, 2006).

Recognizing this need, the 2007-2010 national research agenda for agricultural education and communication included a research priority to "develop and disseminate effective leadership education programs," with emphasis on addressing the needs of current leaders, and strategies for "designing, disseminating, and evaluating" such programs (Osborne, n.d., p. 12). An additional research priority was to "engage citizens in community action through leadership education and development" (p. 12). These national research priority 
areas clearly state the need for intentional reflection and planning with leadership development programs.

\section{Guiding Questions for Leadership Development Programs}

Leadership development programs come in many forms, and there is no one set model that will work for all (Byrne \& Rees, 2006; Caffarella, 2002; Cacioppe, 1998). Generally, there is a lack of research detailing which program models are most effective (Conger, 1992). Some scholars and practitioners have proposed models for leadership program design, but they fail to agree on a unifying theory of leadership development (Hackman \& Wageman, 2007).

In response to these program development issues, the International Leadership Association (ILA) developed Guiding Questions: Guidelines for Leadership Education Programs. "More than 70 leadership educators contributed at one level or another to this project" (Ritch \& Mengel, 2009, p. 217). The guiding questions "explore the content and context of leadership programs" (Ritch, 2010, p. 3) in an effort to guide program design and assessment. The questions were designed to "evoke answers that help leadership educators make important choices about the quality, comprehensiveness and focus of their programs" (p. 2).

To effectively develop a program, practitioners must address questions in each of five areas: (a) the context of the program, (b) a conceptual framework for the program, (c) the required content, (d) appropriate teaching and learning strategies, and (e) the desired learning outcomes and methods of assessing the program. The starting point is program context, which can be framed in terms of various "categories of identity, sector, academics, place, discipline, organization, field of practice, and field of leadership" (Ritch, 2010, p. 9).

\section{Agriculture as a Context for Leadership Development}

Among the different contexts for leadership development, the field of agriculture presents its own unique challenges (Bradshaw \& Rudd, 2009; Kaufman, Rateau, Ellis, Kasperbauer, \& Stacklin, 2010). The agricultural community faces a wide range of complex contextual challenges, including volatile commodity markets, increased regulatory requirements, agricultural illiteracy, food security issues, changing demographics, natural resource depletion, and economic survival. Not only is agriculture complex and diverse, it is becoming more specialized and facing greater confrontation from external groups. Leaders within this community must be able to function amidst the turmoil and move the community forward. The future of agriculture is dependent upon local leaders guiding advocacy efforts related to change (Diem \& Nikola, 2005). 
Agricultural leadership programs have been reported as having a history of more than 75 years in the United States (Kelsey \& Wall, 2003). However, the majority of available literature on modern programs traces their roots to the Kellogg Farmers Study Program (KFSP), which began at Michigan State University in 1965 (Carter, 1999; Case, I. H., 2005; Helstowski, 2001; Lindquist, n.d.). The founders of the KFSP recognized that agriculture was growing more complex and effective leadership was needed in order to protect and guide the future of the industry (Miller, 1976). From the beginning, the KFSP consisted of "workshops and travel seminars intended to provide participants with an understanding of the social, economic, cultural, and political dimensions of public problems" (Howell, Weir, \& Cook, 1982, p. 2). "The goal of the program was to provide young agricultural and rural leaders with a broader view of society, as well as a greater sense of the world and how they fit into the bigger picture" (Helstowski, 2001, p. 1). Intended KFSP outcomes included both personal and professional growth, ranging from expansion of personal perspectives and self-esteem to greater decision-making and involvement in leadership positions.

During the 1980s, the International Association of Programs for Agricultural Leadership (IAPAL) was formed as a consortium of leadership development programs similar to the KFSP (Lindquist, n.d.). According to Pope (n.d.), the purpose of IAPAL is to enhance leadership development and facilitate the dissemination of valuable information to administrators who conduct their individual programs. By the year 2000 agricultural leadership programs in the United States had graduated over 7,200 participants and received over \$15 million in financial support (Case, I. H., 2005; Helstowski, 2001). IAPAL currently includes 41 active programs - 36 in the United States, 2 in Canada, and 3 outside North America (Waldrum, 2009).

Despite the success of the Kellogg Farmers Study Program (KFSP) and the programs that spawned from that model, important questions remain for today's leadership development programs in agricultural contexts. After nearly half a century, is the KFSP model still valid? What do the successful programs look like today? How well do the IAPAL programs align with the programming needs of the agricultural community in the $21^{\text {st }}$ century?

\section{Purpose and Objectives}

The purpose of this study was to describe agriculture community members' desires for leadership development programming as represented by and compared to programs associated with the International Association of Programs for Agricultural Leadership (IAPAL). The specific research objectives include the following: 
- Describe the profile of leadership development programs associated with IAPAL.

- Describe the agricultural community's interest in a new leadership development program, as perceived in a state that does not have an IAPAL program.

- Identify guiding parameters for an emerging leadership development program, as perceived by key stakeholders within Virginia's agricultural community.

\section{Procedures}

Though the purpose and objectives frame this paper as a report on a formal research project, it was not conceptualized as a research study until after plans for an agricultural leadership program came to fruition in Virginia. Recognizing that the data collected along the way would be valuable to others desiring to develop a similar program, the authors of this paper embarked on a retrospective analysis of the data that contributed to the new program plan. Accordingly, this study can be thought of as a retrospective case study. As a case study, the findings are not generalizable. However, the organization of the data into the identified research objectives may allow for extrapolation of the findings for use in similar program development efforts.

The study involved a mixed-methods approach, akin to the explanatory sequential design, beginning with quantitative data collection and concluding with a qualitative research phase to explain the quantitative results (Creswell, 2011). This particular study had three distinct phases:

- Investigate profile of existing programs through face-to-face survey with program directors.

- Explore program interest in Virginia through a mailed survey with key leaders from the target community.

- Explain the program interest and expectations through focus group sessions in the form of a face-to-face meeting with stakeholders.

The following paragraphs describe in more detail the process and participation in each phase of the research. Each phase is associated with a specific research objective. 
For objective one, the researchers developed a questionnaire for program directors who were current members of the International Association of Programs for Agricultural Leadership (IAPAL). This survey was conducted face-to-face during the 2007 annual IAPAL meeting in Miami, FL. The questionnaire included questions in the following areas - program structure and participant demographics, program evaluation, program staffing and administration, board of directors/advisory committees, alumni associations, and communications. Questions were developed based on the researchers' experience with IAPAL programs. All of the questions focused on confirmable facts (i.e., participation numbers), so social desirability bias and similar validity issues were not a serious concern. Of the 21 program directors in attendance at the IAPAL meeting, 19 completed the questionnaire for a completion rate of $90.5 \%$. The respondents represented programs within university systems, foundations, independent organizations, and partnerships. Although the majority of respondents represented programs in the United States, two program directors were from Canada. Because no effort was made to follow-up with non-respondents, the findings are limited to those who completed the questionnaire.

In pursuit of objective two, the researchers developed a questionnaire for use with stakeholders in a state without an IAPAL program. The questionnaire was developed based on the leadership program development literature as well as findings from objective one. The initial draft of the questionnaire was reviewed by an expert panel, and the panelists offered suggestions for question content and wording. The questionnaire was designed to be administered via United States Mail to leaders identified in the Virginia Department of Agriculture and Consumer Services' Directory of Agricultural and Consumer Organizations. To ensure geographic representation, researchers added county Farm Bureau presidents to the study population. Efforts to obtain current contact information for each organization and individual yielded a target population of 252 individuals. To promote a high response rate, the researchers applied Dillman's (2007) tailored design method for mail surveys. The contacts included a prenotice letter, the initial survey mailing, a reminder postcard, a replacement survey mailing, and then phone calls to a random sample of non-respondents. However, the phone calls failed to yield sufficient data for assessing non-response bias. Accordingly, the findings are limited to those who responded.

Among those invited to participate, 153 submitted usable responses for a response rate of $60.7 \%$. Participants were $78 \%$ male, with an average age of 56 years, and an average of 18 years in leadership roles with agricultural organizations. Participants' organizational affiliations reflect the following areas of agriculture aquaculture \& marine, dairy, education, environment, equine, finance, food industry, forestry, general farm organizations (i.e., Farm Bureau), grains, 
livestock (including poultry), marketing, nursery and horticulture, and specialty crops.

For objective three, the researchers held a meeting with 24 key stakeholders for the prospective program in Virginia, and focus group sessions were held as part of that meeting. Participants were identified based on their ability to represent a unique perspective of the agricultural community in Virginia. One-third of the meeting participants had participated in the mailed survey (completed as part of objective two). Similar to the mailed survey participants, the focus group participants' organizational affiliations reflected the following areas of agriculture: aquaculture and marine, dairy, education, environment, equine, finance, food industry, forestry, general farm organizations (i.e., Farm Bureau), grains, livestock (including poultry), marketing, nursery and horticulture, and specialty crops. In the recruitment efforts for the meeting, participants were told that part of the purpose of the meeting was to validate findings of recent research concerning the need for leadership development programming within Virginia's agricultural community. The meeting began with a review of the related research and presentations by representatives from programs affiliated with IAPAL. Participants then worked in small groups to discuss and identify preferences for the following aspects of a new program:

- Program mission, vision, and objectives.

- Appropriate length and frequency of seminars and program.

- Prospects for travel (including in-state, national, and international).

- Criteria and characteristics of program participants.

- Topics, locations, and resources for seminars.

- Tuition and financial support.

Following the meeting, researchers emailed the meeting notes to the participants and inviting them to reply with additions or corrections. This form of member checks helps improve the trustworthiness of the findings (Lincoln \& Guba, 1985).

\section{Findings}

The researchers investigated each study population and related objective separately. The findings are organized accordingly. 


\section{Objective 1: Describe Profile of IAPAL Programs}

The survey of IAPAL programs revealed a profile of existing leadership development programming in the context of agriculture (Table 1). The oldest program was initiated in 1965; the most recent program was initiated in 2003. The average lifetime of the programs surveyed was 24 years. The average length of a program class was 21 months, with an average of 12 seminars held during that time span. On average, 2 of the 12 seminars were held outside of the program's home state/province. Some program directors reported that $100 \%$ of seminars were agriculturally related, whereas other program directors reported less than 5\% of seminars being agriculturally related. The average percent of agriculturally related content was $31 \%$. Program directors reported that $63 \%$ of participants in their most recent class were male and the majority (53\%) was from nonfarm households. The average age of program participants was 38 years old.

Table 1

Profile of programs associated with the International Association of Programs for Agricultural Leadership $(n=19)$.

\begin{tabular}{lrr}
\hline & $M$ & $S D$ \\
\hline Years in existence & 24 & 8.8 \\
Number of program alumni & 370 & 267.2 \\
Number of participants in most recent class & 26 & 5.9 \\
Program length in months & 21 & 3.3 \\
Number of class meetings during program & 12 & 2.2 \\
Number of class meetings held outside program & 2 & 0.7 \\
$\quad$ state/province & & \\
Tuition fee per class participant (U.S. \$) & $\$ 2,974$ & $1,913.3$ \\
Total program cost per participant (U.S. \$) & $\$ 14,337$ & $6,741.2$ \\
\hline
\end{tabular}

Among the IAPAL programs studied, the average tuition/participant fee per class member was $\$ 2,974$. In contrast, the average total program cost per class member was $\$ 14,337$. The gap between tuition and actual cost was bridged through a variety of sources of financial support (Figure 1). All of the program directors indicated that individual seminars are evaluated by current class members. However, only $37 \%$ of programs have conducted a program evaluation with stakeholders. The identified barriers to program evaluation included time, costs, and methods. 


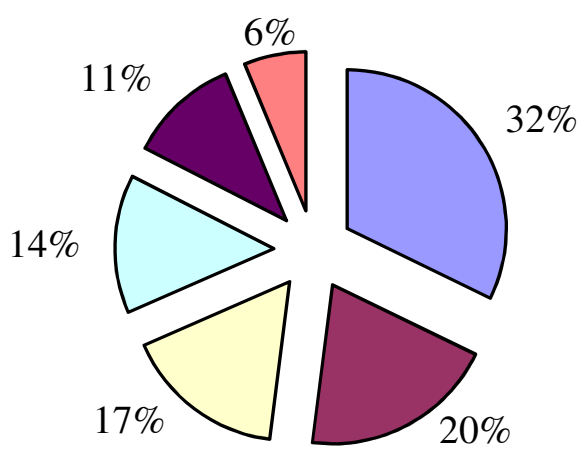

口Donations

$\square$ Participant Tuition

$\square$ Foundation / Endowment

$\square$ Administrative Unit Support

-Legislative Appropriation

口Other

Figure 1. Sources of financial support for programs associated with the International Association of Programs for Agricultural Leadership $(n=19)$.

Most of the IAPAL programs were housed within a university system, with more than half administered through their Land-Grant University's Extension system. Program seminars were being delivered through a variety of means, including field experience, lectures/classroom activities, panel discussions, readings, and technology. The administrative leaders for the IAPAL programs were dividing their time among a variety of tasks, with $39 \%$ of time spent on program planning, $22 \%$ of time spent on fundraising, $21 \%$ of time spent on administrative tasks, and $16 \%$ of time spent on recruitment.

\section{Objective 2: Describe Interest in a New Leadership Program}

A majority of survey participants, $94 \%(n=144)$, indicated a desire for leadership development programming beyond current opportunities for Virginia's agricultural community. Among a list of 25 potential leadership program outcomes, those of greatest interest included:

- "Advocacy for the agricultural community."

- "Access to new agricultural information and skills."

- "New partnerships and collaboration across the agricultural community."

- "Awareness of new technologies that support agricultural production and services."

- "Knowledge of best practices for a viable agricultural industry."

One survey participant clarified expectations by adding the following comments: 
Now more than ever, agriculture needs leaders that are engaged, trained, and competent in advocacy of agricultural issues.

Regulations stand as the single greatest threat to agriculture.

Knowing how to tell your story effectively, listen to other stories and assimilating all of them into a plan for agriculture that allows our industries to regain profitable and viable, yet in compliance with the latest regulations and technologies, is critical. Agriculture must be engaged with local, state, and national elected officials and organizations if we are to survive long-term.

The agricultural leaders surveyed also provided input on a variety of questions related to program design (Table 2). Most respondents (77\%) believed that both emerging and experienced leaders should be included together in an agricultural leadership program. Regarding program length, 65\% of survey respondents expressed interest in a program that spans one year or more. With respect to travel, $80 \%$ expressed a desire for inclusion of on-site experience in diverse areas of Virginia, 35\% expressed a desire for inclusion of on-site experience in another region of the United States, and 12\% expressed a desire for on-site experience outside the United States.

With respect to program delivery mechanisms, "interactive workshops" was the most desired format, followed by "experiential activities," "conference attendance," and "classroom instruction." The least desired format was "online communities, lectures, and services." One survey participant clarified the expectations by offering the following comments:

The proper blend of instruction with experiential activities, social gatherings and other mechanisms is sometimes tricky to achieve. Too much of any one can render a program ineffective. For example, class members love experiential activities, but you must be careful to not become simply an ag tour group. Even when on tour - the purpose is leadership development, and that can be found in many places - not just ag - but certainly within ag as well.

Among preferred host organizations, 70\% of Virginia's agricultural leaders identified their land-grant university's college of agriculture as a preferred host for the desired program. In the "check all that apply" list, the next most preferred hosts included Virginia Cooperative Extension, the Virginia Farm Bureau Federation, and the Virginia Agribusiness Council. Other listed organizations were identified by less than one-third of respondents. 
Table 2

Virginia agriculture leaders' design preferences for a leadership development program $(n=144)$

Target Audience

Emerging leaders Percent Agreement

Experienced leaders $5 \%$

Both emerging and experienced leaders together $2 \%$

Both emerging and experienced leaders, in separate

$77 \%$ programs

Program Length

6-month program

$30 \%$

1-year program

$41 \%$

2-year program

$17 \%$

3-year program

$7 \%$

Other

$5 \%$

Meeting Frequency

1-2 day seminars every month

$60 \%$

3-4 day seminars every two months

$14 \%$

5-7 day seminars every three to four months

$3 \%$

Other

$23 \%$

Travel Expectations

Only local travel and experiences

$17 \%$

On-site experience in diverse areas of Virginia $\quad 80 \%$

On-site experience in another region of the U.S. $35 \%$

On-site experience outside the U.S. $12 \%$

Other

$8 \%$

More than three-fourths of survey respondents indicated that their professional organization would likely be willing to sponsor potential participants (Figure 2). Most indicated likely sponsorship levels of less than $\$ 1,000$; one individual indicated likely sponsorship of $\$ 3,500$ or more. Collectively, survey responses suggest that organizations would be willing to contribute about $\$ 75,000$.

According to one participant, "organizational sponsorship for cost share may be limited due to tightening budgets and available funds." 


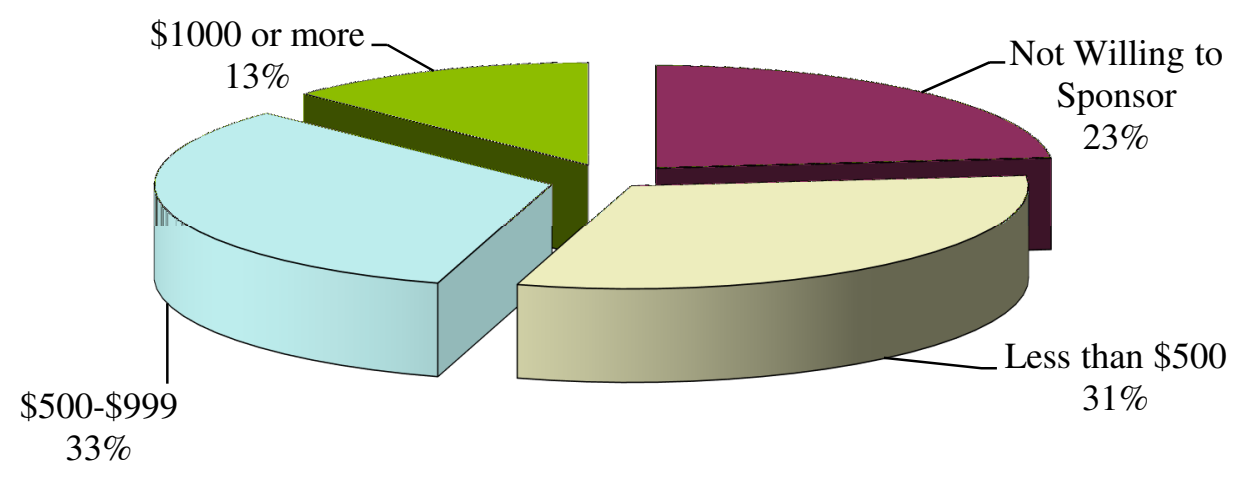

Figure 2. Virginia agricultural organizations' likely sponsorship of program participants in a comprehensive leadership development program $(n=144)$.

\section{Objective 3: Identify Parameters for an Emerging Program}

With respect to objective three, stakeholder meeting participants reinforced the findings from prior research. Regarding a program mission, some consensus was obtained on the following statement: "Develop leaders who can effectively engage all sectors of Virginia Ag to create collaborative solutions and promote agriculture inside and outside of the industry." A similar statement was generated for the program vision: "Virginia agriculture will provide a sustainable future for our industry by maximizing our potential for successful growth through a system of networking, collaborative decision making, and development of strong Ag leaders."

In the discussion of program structure, participants expressed a desire for a twoyear program with seminars two to three days in length on alternating months. They also emphasized the need for travel as a way of getting program participants out of their comfort zone and exposing them to the state's diversity. As for travel outside the state, the stakeholders highlighted the value of international experience. They acknowledged concerns about the added expense of international travel, but prioritized it over domestic travel outside the state.

As for a target population, stakeholders emphasized the need for diversity within each program class. Specifically, they discussed the need for diversity in age, gender, culture, geographic representation, sector of industry, education, and leadership experience. The stakeholders were hesitant to identify age restrictions but suggested the minimum preferred age may be 25 years old. They recognized the need to serve individuals who have a "vested interest in agriculture," but they defined that interest broadly. The stakeholders suggested that an ideal class might be composed $50 \%$ of agricultural producers and $50 \%$ of individuals with 
supporting interests. The preferred class size was 20-25 participants, with a maximum of 30 participants per class.

\section{Discussion, Conclusions, and Recommendations}

As highlighted in the ILA's Guiding Questions (Ritch, 2010), the context of the program is an important consideration when assessing and preparing for quality leadership education and development. All leadership education practitioners need to begin their assessment and planning processes with a thorough understanding of their individual program contexts. Those contexts can highlight "important choices about the quality, comprehensiveness and focus of their programs" (p. 2).

The issue of context can be framed and interpreted a wide variety of ways, but it is helpful to start by considering what is known about programs that have been designed to serve a similar audience. This multi-level study provided insight to the current practices and desire for leadership development programming in the context of agriculture. Leadership education practitioners who work within the context of agriculture should consider the findings from this study and their relevance for further application.

Based on the findings from this study, the goals and structure of the Kellogg Farmers Study Program (KFSP) have lived on through programs affiliated with the International Association of Programs for Agricultural Leadership (IAPAL). The IAPAL programs are diverse, but they continue to reflect the broad goal of the KFSP, "to provide young agricultural and rural leaders with a broader view of society, as well as a greater sense of the world and how they fit into the bigger picture" (Helstowski, 2001, p. 1). In addition, they continue the use of workshops and travel seminars as the primary approach to leadership education and development.

Agricultural leaders who are unfamiliar with the KFSP model still express program preferences that align with the model. This can be seen within their preferences for program outcomes, structure, and delivery mechanisms. When Virginia agriculture leaders considered existing opportunities for leadership development for the agricultural community they wanted something more, such as a program like those currently in IAPAL which may be the answer.

The primary outcome of the stakeholder meeting was a request to build a program similar to the IAPAL programs across the United States. Accordingly, a specific program plan was created and a director was hired to launch the program. This continued replication of the KFSP and the related IAPAL programs provides 
further validation of the model developed at Michigan State University in 1965. Despite the fact that the model is nearly a half century old, key components of the model remain relevant for leadership development in agriculture.

The findings reported in this paper are not generalizable to other states and programs. However, experts in program development and evaluation are increasingly promoting the value of extrapolation for guiding program development. Without violating principles of generalizability, Gargani and Donaldson (2011) point out that information on past programs can be used to predict future results of other programs. It is in this spirit that practitioners can use the findings presented here to develop and improve their own programs.

Program context is not the end for assessing and planning for leadership education and development. Practitioners need to continue through the remaining aspects of the Guiding Questions document, including conceptual framework for the program, required content, teaching and learning strategies, and desired outcomes. The fact that less than half of the IAPAL programs have conducted program evaluations with stakeholders is disturbing, particularly considering the amount of stakeholder support that is required to sustain the programs. As an association designed to support program administrators, IAPAL should seek out ways to promote and support more comprehensive program evaluation.

\section{Acknowledgement}

Portions of this research were funded by the Virginia Agricultural Council. 


\section{References}

Bradshaw, R., \& Rudd, R. (2009). A leadership development needs assessment for Virginia Farm Bureau Young Farmers. Proceedings of the Southern Region Conference of the American Association for Agricultural Education, 2009, 372-386.

Byrne, J. C., \& Rees, R. T. (2006). The successful leadership development program: How to build it and how to keep it going. San Francisco: Pfeiffer.

Cacioppe, R. (1998). An integrated model and approach for the design of effective leadership development programs. Leadership \& Organization Development Journal, 19(1), 44-53. doi:10.1108/01437739810368820

Caffarella, R. S. (2002). Planning programs for adult learners: A practical guide for educators, trainers, and staff developers. San Francisco: Jossey-Bass.

Carter, H. S. F. (1999). Evaluation of the Florida Leadership Program for Agriculture and Natural Resources. University of Florida, Gainesville.

Case, I. H. (2005, Summer). Leading ag's way: Leadership programs develop spokespersons for agriculture. Farm Forum, 25. Retrieved from http://www.caseih.com/files/tbl_s33Publications/PublicationPDF128/1111 /AGISSUESSU05U.PDF

Conger, J. (1992). Learning to lead: the art of transforming managers into leaders. San Francisco: Jossey-Bass.

Creswell, J. W., \& Clark, V. L. P. (2011). Designing and conducting mixed methods research ( $2^{\text {nd }}$ ed.). Thousand Oaks, CA: Sage.

Day, D.V. (2001). Leadership development: A review in context. Leadership Quarterly, 11(4), 581-613. doi:10.1016/S1048-9843(00)00061-8

Diem, K. G., \& Nikola, M. P. (2005). Evaluating the impact of a community agricultural leadership development program. Journal of Extension [Online], 43(6) Article 6RIB5. Available at: http://www.joe.org/joe/2005december/rb5.shtml 
Dillman, D. A. (2007). Mail and internet surveys: The tailored design method: 2007 update with new Internet, visual, and mixed-mode guide (2nd ed.). New York: John Wiley \& Sons.

Eich, D. (2008). A grounded theory of high-quality leadership programs: Perspectives from student leadership development programs in higher education. Journal of Leadership \& Organizational Studies, 15(2), 176187. doi:10.1177/1548051808324099

Gargani, J., \& Donaldson, S. I. (2011). What works for whom, where, why, for what, and when? Using evaluation evidence to take action in local contexts. New Directions for Evaluation, 2011(130), 17-30. doi: 10.1002/ev.362

Hackman, J. R., \& Wageman, R. (2007). Asking the right questions about leadership. American Psychologist, 62(1), 43-47. doi:10.1037/0003066X.62.1.43

Helstowski, L. W. (2001). The legacy of the ag leadership development program: Rich heritage cultivates future opportunities (Booklet No. 534). Battle Creek, MI: W.K. Kellogg Foundation. Retrieved from http://www.leadershiponlinewkkf.org/learningcenter/pubs/ag_leadership/ Ag_Leadership_Booklet.pdf

Howell, R. E., Weir, I. L., \& Cook, A. K. (1982). Development of rural leadership: Problems, procedures, and insights. Battle Creek, MI: W. K. Kellogg Foundation.

Kaufman, E. K., \& Carter, H. S. (2005). Agricultural leadership development: From networking to application. Journal of Leadership Education, 4(2), 66-75.

Kaufman, E. K., Rateau, R. J., Ellis, K. C., Kasperbauer, H. J., \& Stacklin, L. R. (2010). Leadership program planning: Assessing the needs and interests of the agricultural community. Journal of Leadership Education, 9(1), 122143.

Kelsey, K. D., \& Wall, L. J. (2003). Do agricultural leadership programs produce community leaders? A case study of the impact of an agricultural leadership program on participants' community involvement. Journal of Agricultural Education, 44(4), 35-46. doi:10.5032/jae.2003.04035 
Lincoln, Y. S., \& Guba, E. G. (1985). Naturalistic inquiry. Newbury Park, CA: Sage.

Lindquist, J. (n.d.). The International Association of Programs for Agricultural Leadership [website]. Retrieved from http://www.ksre.ksu.edu/karl/DesktopDefault.aspx?tabid=58

Miller, H. L. (Ed.) (1976). The Kellogg Farmers Study Program: An experience in rural leadership development. Battle Creek, MI: W. K. Kellogg Foundation.

Osborne, E. W. (Ed.) (n.d.). National research agenda: Agricultural education and communication, 2007-2010. Gainesville, FL: University of Florida, Department of Agricultural Education and Communication.

Pope, L. S. (Ed.) (n.d.). General Guidelines of the International Association of Programs for Agricultural Leaders (IAPAL). College Station, TX: IAPAL.

Raelin, J. (2004). Don't bother putting leadership into people. The Academy of Management Executive, 19, 131-135. doi:10.5465/AME.2004.14776184

Riggio, R. (2008). Leadership development: The current state and future expectations. Consulting Psychology Journal: Practice and Research, 60(4), 383-392. doi:10.1037/1065-9293.60.4.383

Ritch, S. W. (Ed.) (2010). Guiding questions: Guidelines for leadership education programs. College Park, MD: International Leadership Association. Retrieved from http://www.ila-net.org/Communities/LC/GuidingQuestionsFinal.pdf

Ritch, S. W., \& Mengel, T. (2009). Guiding questions: Guidelines for leadership education programs. Journal of Leadership Education, 8(1), 216-227.

Waldrum, J. (Ed.) (2009). International Association of Programs for Agricultural Leadership (IAPAL) directory. Little Rock, AR: IAPAL. 


\section{Author Biographies}

Eric K. Kaufman is an assistant professor in the Department of Agricultural and Extension Education at Virginia Tech, where he teaches leadership courses for student in all disciplines at the graduate and undergraduate levels. He coordinates Virginia Tech's graduate certificate program in Collaborative Community Leadership and assists in coordination of the undergraduate Leadership and Social Change minor. Eric holds a Bachelor of Science degree from Ohio State University; both his Master's and Doctorate of Philosophy degrees are from the University of Florida. Eric's research interests include collegiate leadership education and leadership development with adults in community and volunteer settings.

Richard J. Rateau is a recent Ph.D. graduate from Virginia Tech where he completed his doctoral program in the Department of Agricultural and Extension Education. At Virginia Tech he has taught undergraduate courses in communications and leadership. He recently completed a rewarding 30-year career in the poultry and red meat industries, working in various leadership, strategic planning, and management capacities. He earned an M.B.A. at Queens University and has a B.S. in Agricultural Sciences from Auburn University. His research interests include leadership development and employability skills of college graduates leading to success in the workplace.

Hannah S. Carter is assistant professor in leadership development at the University of Florida in the Department of Agricultural Education and Communication. Within this appointment she directs a leadership development program for adults within private industry throughout Florida. In addition, she teaches courses in both the undergraduate and graduate level in organizational leadership and team leadership. She obtained her B.S. in environmental science with a concentration in biology at the University of Maine at Presque Isle. Her M.S. and Ph.D. are both in agricultural education and communication from the University of Florida. Her current research interests are in adult leadership programming including both program development and determining impacts of leadership programming.

L. Rochelle Strickland is a Public Service Assistant within the department of Agricultural Leadership, Education and Communication and is the Program Manager for LEAD21, a national leadership development program for faculty, specialists, program and team leaders, research station and center directors, district and regional directors, department heads and chairs, and others in land grant universities' colleges of agricultural, environmental, and human sciences and USDA/NIFA. She plays a key role in the coordination of the development 
and implementation of LEAD21. Dr. Strickland is currently developing an adult leadership development program for individuals involved in Virginia's agricultural and natural resources industries. Her research focuses on evaluating the outcomes and impacts of adult leadership development programs, specifically within the agricultural context to understand best practices for adult education and leadership development. 